\title{
El empresariado de la obra pública y los grupos políticos durante el galvismo. Santa Fe (Argentina), segunda mitad del siglo XIX*
}

\section{Public Works Business Sector and Political Groups during Galvez's Administration. Santa Fe (Argentina), Second half of 19 th Century}

\author{
Romina Garcilazo** \\ Universidad Nacional de Rosario, Rosario, Argentina, \\ email: romina_garcilazo@hotmail.com
}

Resumen. El presente artículo tiene como objetivo analizar, a partir del enfoque de redes sociales, la función adquirida por el empresariado rosarino -ligado a la obra pública-en el ámbito político. Para acercarnos a este tópico, tomaremos como escenario exploratorio la gestión del gobernador José Gálvez en Santa Fe (1886-1890) por haber sido uno de los gobiernos que hizo de la ampliación de la infraestructura urbana un eje central de su gestión y su relación con el empresario más controvertido y dinámico en la obra pública, como fue Juan Canals (uno de los pocos radicados en Santa Fe que se dedicó a esta actividad). El principal aporte del trabajo es ilustrar la complejidad de las tramas vinculares construidas por el empresariado rosarino alrededor de las arcas del poder político santafesino durante dicho periodo, temática escasamente explorada por la historiografía local.

Palabras clave: empresarios; grupos políticos; obra pública; Santa Fe; siglo XIX; redes sociales.

Abstract. This article focuses on the role of entrepreneurs linked to public works of Rosario in the political sphere, from the approach of social networks. We approach to this topic by exploring the administration of Governor Gálvez in Santa Fe (18861890) and his relationship with Juan Canals. Canals was one of the few who engaged in that activity while he was living in Santa Fe and was the most controverted and dynamic businessman in public works at that time. The main contribution of this paper is to illustrate the complex links stablished between business sector in Rosario and political power in Santa Fe during this period. This subject was few explored by local historiography.

\footnotetext{
* El presente artículo recupera algunos planteamientos esbozados en mi tesis doctoral. Véase Garcilazo (2015). La autora agradece los comentarios efectuados por los evaluadores anónimos de la revista América Latina en la Historia Económica.

** Instituto de Investigaciones Socio Históricas Regionales, Consejo Nacional de Investigaciones Científicas y Técnicas.
} 
Key words: businessman; political power; public works; Santa Fe; 19th century; social networks.

Fecha de recepción: 13 de mayo de 2016. Fecha de aceptación: 24 de agosto de 2016.

Canals era un honorable comerciante [...] y mientras los príncipes del juarismo se entregaban en su palacio [...] haciendo y deshaciendo la política del país [...] Canals no se preocupaba más que de puertos, empedrados, palacios, mataderos, obteniendo las concesiones más enormes El Municipio, 1 de septiembre de 1894

\section{INTRODUCCIÓN}

【 a noticia aparecida en El Municipio daba cuenta del protagonismo ejercido por ciertos empresarios locales ligados a la obra pública en Argentina durante la presidencia de Miguel Juárez Celman (18861890). ¿Qué intereses en común unían a empresarios y políticos? ¿Por qué se vinculaba a Canals con los hombres que representaban el poder oficial?

La vinculación entre empresariado y poder político ha sido uno de los temas privilegiados de la historiografía nacional e internacional. La discusión circunscrita al escenario argentino de finales del siglo XIX y principios del Xx ha girado en torno a algunos asuntos problemáticos, por ejemplo la compleja relación entre poder político y clase terrateniente bonaerense (Halperin, 1992; Hora, 2005 y 2009), el accionar del corporativismo empresarial (Jáuregui, 1993; Marchese 1993; Rapalo, 2012; Rocchi, 2000; Valencia, 1993), la confluencia entre intereses político-económicos alrededor de las obras de modernización urbana (Boixaidós, 2000 y 2010; Lotersztain, 2010) y la conformación y el desenvolvimiento político-económico de las burguesías regionales (Bandieri, 2000 y 2005; Bolsi, 2013; Bonaudo y Sonzogni, 1998, 2000 y 2001; Bragoni, 1993 y 1999; Bravo y Campi, 2000; Herrera, 2004 y 2011; Paz, 2003; Richard-Jorba y Bragoni, 1998). En algunas de estas últimas investigaciones se ha llegado a la conclusión de que entre ciertos sectores de la burguesía operó una actitud de acercamiento al Estado, concebido como garante de la viabilidad de sus empresas (Bonaudo y Sonzogni, 2000 y 2001). Los grupos burgueses decimonónicos se insertaron en las redes políticas que les permitieron involucrarse en los negocios ligados, entre otros, a las obras de infraestructura urbana y a la especulación inmobiliaria. Al interior de esas estructuras se construyeron vínculos gestados con el fin de responder a sus propias intenciones y por 
los que circulaban bienes y servicios (Bertrand, 2012, p. 62; Ponce-Leiva y Amadori, 2008, p. 27). ${ }^{1}$

En las últimas décadas, la historiografía ha afirmado que la burguesía rosarina -contrariamente a sus pares capitalinos-si bien no detentó lugares significativos en la política provincial sí se valió de relaciones parentales y vínculos de amistad para influir en las decisiones estatales en su propio beneficio (Bonaudo y Sonzogni, 2000 y 2001; Fernández, Videla y Pons, 1999 y 2000). ${ }^{2}$ A diferencia de otras experiencias al interior de Argentina -como lo acaecido en las provincias de Tucumán o Mendoza- donde los hilos de la política fueron movidos por los sectores que retenían al mismo tiempo el poder económico, la burguesía rosarina tuvo cierta injerencia, aunque no un protagonismo absoluto, en las agendas del Estado provincial (Bonaudo y Sonzogni 2000 y 2001; Bragoni, 1999; Herrera, 2004). Si bien en estos últimos años hemos avanzado en dicha temática, a partir del análisis de algunos proyectos emprendidos por el empresariado ligado a la construcción, aún es necesario bosquejar una mirada de conjunto que nos permita, por un lado, mostrar cuál es el entramado que unió al poder político con el empresariado ligado a la obra pública y, por el otro, cuáles han sido los distintos tipos de negociados que le dieron vida (Garcilazo, 2013, 2015).

Para acercarnos a este tópico tomaremos como escenario la gestión del gobernador José Gálvez en Santa Fe (1886-1890) por haber sido uno de los gobiernos que hizo de la ampliación de la infraestructura urbana uno de los ejes centrales de su gestión y su relación con el empresario más dinámico en la obra pública como fue Juan Canals, uno de los pocos radicados en la provincia que se dedicó a esta actividad ya que con posterioridad dicho negocio fue monopolizado por empresas extranjeras. ${ }^{3}$ Cabe destacar que el caso de Canals es paradigmático, en tanto que representa el prototipo de burgués local que relegado de los cargos políticos a nivel provincial utilizó diferentes mecanismos, en el que las redes sociales cumplieron un papel directriz para obtener beneficios estatales. Sin embargo, el mismo presenta cierta singularidad: por un lado, a diferencia de otros actores -como Carlos Casado, cuyos negocios se circunscribieron a la colonización agrícola, al ámbito bancario y al negocio ferroviario- la trayectoria de Canals se

${ }^{1}$ El artículo de Bertrand, con anterioridad, fue publicado en 1999 en la Revista Mexicana de Sociología, 61(2), 107-135.

${ }^{2}$ Se utilizarán los términos de burguesía y empresariado de manera intercambiable respetando la terminología empleada por los autores.

${ }^{3}$ Distintos estudios han abordado el accionar de las empresas de obras y servicios públicos en Argentina durante la segunda mitad del siglo XIX y principios del XX (Marquiegui y Tartaglia, 2003; Regalsky y Salerno, 2008; Solveira, 2009). 
orientó hacia la obra pública urbana y, por otro, porque su experiencia es considerada fallida al declararse su quiebra luego de la crisis de $1890 .{ }^{4}$

La problemática será guiada por el herramental teórico-metodológico de la red social, ya que esta nos sirve para visibilizar las relaciones entre empresarios y políticos. Para ello, si bien tomaremos como marco referencial la red social en la que esos personajes se encontraban inscritos, nos focalizaremos en algunos de sus "fragmentos", es decir, en los vínculos a partir de los cuales se estructuró. La red es caracterizada como "un conjunto de vínculos latentes que existe porque sus integrantes reconocen tener una serie de obligaciones entre sî" (Pro-Ruiz, 1995, p. 65). Entendemos por vínculo "a los intercambios realizados dentro de la red" (Bertrand, 2012, p. 62).

Este trabajo, desde el punto de vista metodológico, nos ha exigido utilizar una documentación diversa con el objetivo de reconstruir el nodo de relaciones significativas forjadas entre empresariado y poder político (Moutoukias, 1995, p. 224). Dicho corpus está constituido por protocolos notariales, cartas personales del empresario estudiado, prensa adepta y opositora al galvismo y escrituras de sociedades comerciales de los actores ligados a la obra pública. ${ }^{5}$

\section{EMPRESARIADO Y PODER POLÍTICO DURANTE EL GALVISMO}

Hacia la segunda mitad del siglo XIX la provincia de Santa Fe comenzaba a incorporarse exitosamente al modelo agroexportador argentino. El dinamismo que adquirió el área rural profundizó el crecimiento de otros centros urbanos como Rosario. Para 1870, esta ciudad ubicada al sur de Santa Fe se destacó por la intensa actividad de su puerto y por ser uno de los polos ferroviarios más importantes del país. De este modo, Rosario se había

\footnotetext{
${ }^{4}$ Sobre las trayectorias empresariales fallidas véase Lanciotti y Lluch (2010).

${ }^{5}$ Una de las fuentes que tomaremos como insumo de la investigación es la prensa de la época. Durante el siglo XIX la prensa fue uno de los principales medios a partir del cual se hacía política (Alonso, 2004, p. 10). A lo largo del artículo haremos mención, particularmente, a tres diarios: El Municipio, Caramelo y La Capital. El Municipio fue el principal opositor a la política del gobernador Gálvez. Esa posición debe entenderse porque su dueño, Deolindo Muñoz, perteneció, al igual que su denunciado, al Club del Pueblo y fue destituido como ministro de Gobierno de la provincia por el gobernador Zavalla, y reemplazado por Gálvez. Ese hecho consolidó el liderazgo político de Gálvez y sepultó las aspiraciones de Muñoz, quien luego fundaría dicho periódico. El matutino se caracterizó por presentar una línea editorial centrada en las problemáticas que atravesaron a la ciudad y por manifestar, de manera agresiva y directa, sus críticas al gobierno de Gálvez (Fortuny y Rodes, 2005, p. 14; Ventura, 2003, pp. 233-249). Por otra parte, Caramelo representó la voz del oficialismo galvista, y La Capital, cuyo fundador, Ovidio Lagos, pertenecía al Partido Constitucional, expresó una línea editorial que mantuvo cierta independencia respecto a los asuntos públicos (Eujanian y Sánchez-Román, 1993, pp. 117-226).
} 
convertido en un espacio privilegiado de Argentina por su comunicación con el área rural santafesina y los principales núcleos urbanos y puertos del país. Este proceso alentó su crecimiento poblacional que respondía a la oleada inmigratoria, se estima que para 1860 más de $40 \%$ de la población rosarina era de origen extranjero (Videla y Fernández, 2001, pp. 70, 82).

Estas transformaciones fueron orientadas y promovidas desde el Estado. En el escenario nacional las fracciones que disputaban el ámbito político, luego de la caída de Rosas en 1852, fueron las denominadas federales y liberales, esta última escindida en autonomistas y nacionalistas. Las características comunes de estos grupos han sido la aglutinación en torno a personalidades fuertes, la labilidad de sus lealtades y la indefinición de sus bases programáticas, mientras que mantuvieron posiciones divergentes respecto a la relación que debía existir entre Iglesia y Estado (Bonaudo, Sonzogni, 1999, p. 41; Cragnolino, 1986-1987, pp. 426-427). Para la década de 1880, la amalgama liberal-federal se coligó bajo el nombre de Partido Autonomista Nacional. Entre 1880 y 1886 esa fracción se estructuró sobre el liderazgo del presidente Julio A. Roca, y para la etapa precedente, 1886-1890, con Miguel Juárez Celman. ${ }^{6}$ En Santa Fe el autonomismo disputó la arena política con la fracción liberal y se mantuvo en el poder desde la década de 1860 hasta los primeros años del siglo XX. En ese periodo recibió diferentes denominaciones, una de ellas fue Club del Pueblo que, al igual que otros, se caracterizó por ejercer su control mediante la activación de una red de relaciones familiares, de amistad y clientelares, potenciada a través de distintos espacios de sociabilidad. ${ }^{7}$ Sus principales representantes fueron miembros de las familias capitalinas de raigambre colonial dedicadas a la colonización agraria y la actividad comercial (Bonaudo, 1999, pp. 270-271).

El Club del Pueblo tuvo una relación fluctuante con el gobierno nacional. Durante el periodo galvista manifestó fidelidad al liderazgo de Juárez Celman al abandonar su adhesión política a la anterior figura presidencial, representada por Roca. En la arena política provincial, a partir de 1883, disputó su poder con el Partido Constitucional, constituido por un grupo de jóvenes que se habían desprendido del autonomismo provincial. En el municipio de Rosario esas fracciones políticas compitieron en el escenario

\footnotetext{
${ }^{6}$ Durante este primer periodo el Partido Autonomista Nacional debió enfrentarse a una heterogénea oposición, constituida por el Partido Nacionalista -cuya figura más representativa era el ex presidente Mitre-, algunos sectores del ex autonomismo porteño, la Unión Católica (conformada con el objeto de oponerse a las leyes laicas del presidente Roca) y la Unión Cívica de la Juventud, integrada por estudiantes universitarios (Gallo, 2000, p. 529).

${ }^{7}$ Se utiliza el término partido-constelación porque la organización partidaria asume: "la forma de una constelación [...] que en su dinámica ponía en movimiento una compleja articulación de redes, asociaciones y vehículos culturales" (Bonaudo, 2015, p. 31).
} 
electoral, logrando el Club del Pueblo imponer sus candidatos a los cargos municipales (Megías, 2010, p. 38). Cabe recordar que los municipios eran, según la normativa, entes administrativos representantes de los vecinos. Si bien los cargos deliberativos eran elegidos por los habitantes de las ciudades, los ejecutivos, en un principio, fueron ejercidos por el jefe político y por el ministro de Gobierno de la ciudad de Santa Fe, luego por algunos miembros del concejo y, posteriormente, dichas funciones recayeron sobre el intendente, cuyo cargo fue electivo desde inicios de la década de 1880 hasta $1890 .^{8}$

En ese escenario la burguesía rosarina se insertó con cierto éxito en las redes de poder. A pesar de ser este un sector heterogéneo presentaba características que le eran propias, como un origen inmigrante, carácter cosmopolita, marcado ascenso social, preferencia por las actividades comerciales, financieras y especulativas y marginalidad política en tanto que no controlaban los resortes estatales provinciales, además sus funciones políticas locales no fueron ejercidas plenamente ya que debieron supeditarse, en más de una oportunidad, a los mandatos esgrimidos desde la provincia (Fernández, Videla y Pons, 1999-2000, pp. 236, 237 y 241). Sin embargo esto último no impidió que ensayaran una serie de estrategias para vincularse con personajes de la vida política provincial. Ello se evidenció en el papel adquirido en la conformación y el posterior funcionamiento del Banco Provincial de Santa Fe (la institución del crédito público-privada más importante de la provincia), del Ferrocarril Oeste Santafesino (una de las empresas de capitales locales pioneras en el área) y en la adquisición de tierras fiscales (Dalla-Corte, 2009, p. 48).

Durante su gobernación, Gálvez brindó apoyo a esos grupos burgueses, fundamentalmente, por los beneficios estatales otorgados a ciertos empresarios vinculados a la compraventa de terrenos fiscales y a la obra pública provincial. A lo largo de su gestión se llevaron adelante distintas obras de infraestructura urbana, se extendieron las líneas férreas, se estableció la red telegráfica a escala nacional, se refaccionaron edificios emblemáticos (como el antiguo Cabildo de Santa Fe), se construyeron otros (tal fue el caso del Palacio de Justicia en Rosario), se crearon puentes y distintos espacios culturales (Marco, 2002, p. 38).

Uno de los empresarios galvistas más influyentes por su accionar en la obra pública fue Canals, inmigrante catalán que arribó a Rosario en la década de 1870. Gracias a los vínculos previos con la comunidad catalana en dicha ciudad, Canals pudo emplearse en una casa comercial, para luego conformar junto a sus connacionales una sociedad mercantil (Escayola,

\footnotetext{
${ }^{8}$ Ley Orgánica de la Municipalidad sancionada el 19 de diciembre de 1884. Biblioteca Argentina Dr. Juan Álvarez (en delante BA), Rosario, Argentina.
} 
Canals y Cía.), dedicada al comercio de artículos de almacén. Paralelamente fue accionista del Banco Provincial de Santa Fe. Para la década siguiente Canals había extendido sus lazos sociales con la naciente burguesía rosarina. Su enlace matrimonial con Asunción Dam, perteneciente a una de las familias más distinguidas, le permitió acceder a los espacios de poder debido a que su suegro, Juan Dam, fue gerente del Banco Provincial. La década de 1880 no sólo lo tuvo como protagonista en el ámbito empresarial sino también en el espacio político. Durante el periodo 18811883 fue concejal titular por el Club del Pueblo, siendo nuevamente electo ese último año en calidad de suplente. ${ }^{9}$

A mediados de 1886 se evidenció un ascenso económico de Canals debido a la multiplicidad de sus actividades. La trama vincular construida a partir de las sociedades económicas que emprendió con sus connacionales radicados en distintas partes de Argentina o Barcelona lo convirtieron, al igual que otros miembros de la burguesía local, en un empresario multimplantado. Algunas de sus inversiones abarcaban la actividad industrial, el negocio inmobiliario -urbano y rural-, el ámbito bancario y los sectores del transporte y la construcción (Garcilazo, 2013, pp. 116, 119-121).

A principios del año 1890 el estado patrimonial del empresario daba cuenta que la inversión en obra pública ascendía a la cifra de 13100000 pesos $\mathrm{M} / \mathrm{N}$ (contando su desembolso en los proyectos más significativos), valor que representaba más de 50\% del total de su patrimonio (Garcilazo, 2015 , p. 169). Entre las obras que intentó llevar a cabo durante la etapa galvista se destacan el adoquinado de calles en Rosario, la construcción de mataderos y mercados de abasto -ambos proyectos acordados con la municipalidad de Rosario -, la edificación del Palacio de Justicia y la cárcel provincial -establecidos con el gobierno de la provincia-, además de la ejecución de las secciones norte y sur del puerto de la ciudad, convenidas con el Estado nacional. Sin embargo, y debido a los efectos que la crisis económica de 1890 tuvo en algunos sectores de la economía, como la obra pública (por la irrupción del crédito externo) y la especulación inmobiliaria (por la desvalorización del precio de la tierra) los proyectos de Canals, al igual que la mayoría de las obras públicas en el país, sólo pudieron ser ejecutados parcialmente. Algunas de sus construcciones fueron traspasadas a otras empresas (tal como ocurrió con el adoquinado de calles) y otras no pudieron llevarse a cabo o bien porque se rescindieron sus contratos (Palacio de Justicia y cárcel provincial) o porque no se aprobaron sus pro-

${ }^{9}$ Expedientes del Concejo Deliberante (1899). Complementario de Archivo 1880 al 1899, libro C, f. 1483, Archivo Histórico del Concejo Municipal de Rosario. Rosario, Argentina (en adelante AHCMR). 
yectos (mataderos y mercados del abasto) (Garcilazo, 2015, pp. 211-256; Lanciotti, 2009, p. 172).

La dificultad para llevar a cabo las obras emprendidas se explica no sólo por la situación económica del país, sino también por la falta de solvencia del empresario. Su estado patrimonial para el año 1890 demostraba que su pasivo superaba en más de cuatro veces a su activo. ${ }^{10}$ Esta situación en parte se debe al grado de endeudamiento experimentado por el empresario para la puesta en marcha de algunas de sus construcciones y porque las ramas de la economía donde tenía colocado su capital -sector inmobiliario, obra pública y mercado bursátil- se vieron afectadas por la debacle. Como resultado de ello, los bienes de Canals fueron absorbidos por los bancos Provincial de Santa Fe e Inglés Río de la Plata (Garcilazo, 2015, p. 272; Lanciotti, 2009, p. 173).

\section{LA TRAMA DE VÍNCULOS QUE IMPRIMIÓ LA LÓGICA A LA OBRA PÚBLICA SANTAFESINA}

En la década de 1880 no existía en Santa Fe una normativa provincial que regulara el funcionamiento de la obra pública. Debido a ello se tomó como base la ley nacional de 1876, que determinaba los mecanismos de licitación, adjudicación y ejecución de las obras (Marco, 2002, p. 52). ${ }^{11}$ Sin embargo, en la carta magna provincial se hacían algunas referencias al tema. En uno de sus artículos, se establecía que el Estado podía celebrar contratos con empresas que fuesen objeto de utilidad provincial, los cuales debían ser aprobados por la legislatura (Ramos, 1916, p. 199).

Sin una ley provincial propia y carente de un aparato estatal eficiente para estos fines durante los años ochenta, las obras en la provincia se efectuaron bajo un control gubernamental endeble. Debido a ello las empresas no brindaron un buen servicio y los usuarios fueron víctimas de la ineficiencia del Estado (Marco, 2002, p. 53).

${ }^{10} \mathrm{El}$ activo de Canals era de 4364090 pesos M/N constituido por inversiones orientadas al sector inmobiliario, a la obra pública, al mercado bursátil y a bienes muebles. Mientras que su pasivo era de 17775045 pesos M/N, conformado por deudas a terceros y por obligaciones contraídas en el ámbito de la construcción y en el sistema bancario. Carta de Juan Canals a Alfredo de Arteaga, 1890, Tribunales Comerciales, f. 82. Archivo General de la Nación. Buenos Aires, Argentina (en adelante AGN).

${ }^{11}$ Algunos artículos de la citada ley afectaban los negocios del empresario en tanto que establecían cláusulas sobre la respetabilidad en los términos de la culminación de las obras y los plazos de pago estipulados por el Estado. Por otro lado, en la citada normativa se determinaba que el precio de los materiales no podía modificarse con posterioridad a la firma del contrato. Este elemento constituía uno de los riesgos a los que se enfrentaba el empresariado debido a la fluctuación del precio de los insumos. Ley Nacional de 1876 (1876, pp. 339, 341). 
Argentina, a diferencia de otros países latinoamericanos, adoptó el sistema de concesión, por el cual el Estado depositaba en los particulares la construcción y comercialización del servicio, garantizándoles el derecho exclusivo de explotación. Los gobiernos beneficiaron a estos sectores con subvenciones, exenciones fiscales o subsidios (Connolly, 1993, pp. 4-6). De este modo el Estado brindó a los empresarios garantías de acumulación que eran extensivas al ámbito ferroviario y de la colonización. Referente a los proyectos de Canals, algunas concesiones fueron estipuladas por el término de 30 años, como la construcción del Palacio de Justicia. Por otro lado, en los contratos se establecieron algunas cláusulas que exceptuaban al empresario del pago de algunos impuestos, como los concernientes a la introducción de materiales de la construcción, y se le daban garantías de utilidad mínima -en el caso del contrato referido al Palacio de Justicia el Estado provincial se comprometió a otorgarle 5000 pesos M/N mensuales. $^{12}$

Asimismo, cabe recordar que el sistema de concesión está supeditado a la responsabilidad de la financiación y a la comercialización del servicio, obteniendo el concesionario el mayor beneficio de la prestación del servicio que brinda (Connolly, 1999, p. 203). Si nos circunscribimos a los proyectos de Canals, debe decirse que su ganancia variaba según el tipo de construcción. En el caso del adoquinado, la ganancia estaba supeditada al pago que la municipalidad efectuaba por cada calle pavimentada, en lo referente a la construcción del Palacio de Justicia, provenía del alquiler de las oficinas de los agentes judiciales, mientras que en lo concerniente a la construcción de mataderos y mercados, provendría de la explotación de tabladas, mataderos y mercados y del cobro del servicio de barrido y limpieza. ${ }^{13}$ Por su parte, el proponente corría con los gastos de la contratación de la mano de obra y de los materiales. Algunos de los insumos provenían

${ }^{12}$ Juzgado Civil y Comercial, Segunda Circunscripción, actor Juan Canals, demandado Juan Carletti, causa expropiación de un terreno, exp. C-77. 1888. Archivo de Tribunales de Rosario, Rosario Argentina (en adelante ATR). Actas del Concejo Deliberante de Rosario, Cuaderno núm. 12, f. 32, AHCMR.

${ }^{13}$ Municipalidad de Rosario de Santa Fe. Digesto Municipal 1860-1889, 1889, AHCMR; Juzgado Civil y Comercial, Segunda Circunscripción, 1888, actor Juan Canals, demandado Juan Carletti, causa expropiación de un terreno, exp. C-77, ATR; Propuesta de mataderos presentada por Juan Canals, 1890, Expedientes terminados del Honorable Concejo Deliberante de la ciudad de Rosario, f. 192, AHCMR. Si bien no podemos estimar el beneficio económico que el empresario obtuvo por sus proyectos de pavimentación, se sabe que de los 6223753.69 pesos M/N, correspondientes al empréstito que la municipalidad obtuvo para la ejecución de los trabajos, 2669032 pesos M/N fueron pagados a Canals por las obras realizadas. El resto del monto fue transferido a su cuenta en el Banco Provincial. Respecto al Palacio de Justicia el empresario, al no efectivizar la obra, no llegó a cubrir su inversión inicial. El Municipio, 5 de diciembre de 1899; Juan Canals su sucesión hoy su concurso, 1901, leg. 9010, f. 76, Archivo del Poder Judicial de la Nación (en adelante APJN), Buenos Aires, Argentina. 
de Uruguay, tal era el caso de los adoquines que eran introducidos por la firma Canals, Dam y Cía., sociedad integrada por Canals, J. Dam, su cuñado y Perrone, su socio en la capital del país, mientras que otros eran elaborados en la ciudad en la planta industrial de hornos de ladrillos que era propiedad de la empresa. ${ }^{14}$ La vinculación de dichos emprendimientos con el ámbito de la obra pública es uno de los factores que explican la disminución del costo de los materiales en las construcciones de Canals. Este fue uno de los componentes determinantes para que los órganos deliberativos aprobasen sus proyectos.

De las propuestas de Canals sólo una fue presentada al poder ejecutivo provincial al mando de Gálvez -como el Palacio de Justicia-, el resto fue ofertado al poder local. ${ }^{15}$ Sin embargo la facilidad con la que el empresario obtuvo las licitaciones en el ámbito municipal se debieron no sólo a sus capacidades de constructor y a sus habilidades para acceder al sistema crediticio, sino a la trama de vínculos a partir de la que se estructuró la obra pública (Lanciotti, 2009, p. 174). Aunque ello le permitió acceder a dicho negocio no le aseguró su éxito.

Según la normativa, en el proceso licitatorio los proponentes debían seguir cierta forma de operar para recibir la aprobación de los órganos legislativos y deliberativos. En la mayoría de sus proyectos Canals se ajustó a los procedimientos licitatorios, como el adoquinado de calles y la construcción de mataderos y mercados. El Concejo Deliberante aceptó sus propuestas de adoquinado por utilizarse en ellas materiales de mejor calidad y menor costo, en detrimento de la presentada por otros empresarios locales, como Domingo Barraco. Mientras que en la construcción del Palacio de Justicia, si bien no siguió ese mecanismo, al ser una propuesta que él mismo presentó a las autoridades provinciales, recibió la aprobación de los órganos deliberativos. Este era un procedimiento que se adecuaba a la carta constitucional al ser un proyecto considerado de utilidad pública. ${ }^{16}$

La red que incluía a las personalidades intervinientes en la concreción de los proyectos de Canals estaba conformada por políticos ligados a la figura de Gálvez (véase figura 1), como el ministro de Gobierno de Santa $\mathrm{Fe}$, Cafferata, el intendente de Rosario, Larrechea y el concejal Mazza,

${ }^{14}$ Contrato de Juan Gregorini y otros a don Juan Canals, 1888, Protocolo del escribano Javier Munuce, fs. 407-410. Archivo del Colegio Público de Escribanos Segunda Circunscripción Santa $\mathrm{Fe}$, Rosario, Argentina (en adelante ACESCSF).

${ }^{15}$ Una excepción fue el proyecto de construcción del puerto de Rosario acordado con el poder ejecutivo nacional que se llevó a cabo parcialmente, ya que en 1892 el gobierno rescindió el contrato con el empresario. No haremos mención a este emprendimiento ya que excede los objetivos del artículo.

${ }^{16}$ Actas del Concejo Deliberante de Rosario, 1888, Cuaderno núm. 12, f. 32, AHCMR; Juzgado Civil y Comercial, Segunda Circunscripción, actor Juan Canals, demandado Juan Carletti, causa expropiación de un terreno, 1888, exp. C-77, ATR. 


\section{FIGURA 1. VÍNCULOS ENTRE EMPRESARIADO Y PODER POLÍTICO EN TORNO A LA OBRA PÚBLICA. SANTA FE (1886-1890)}

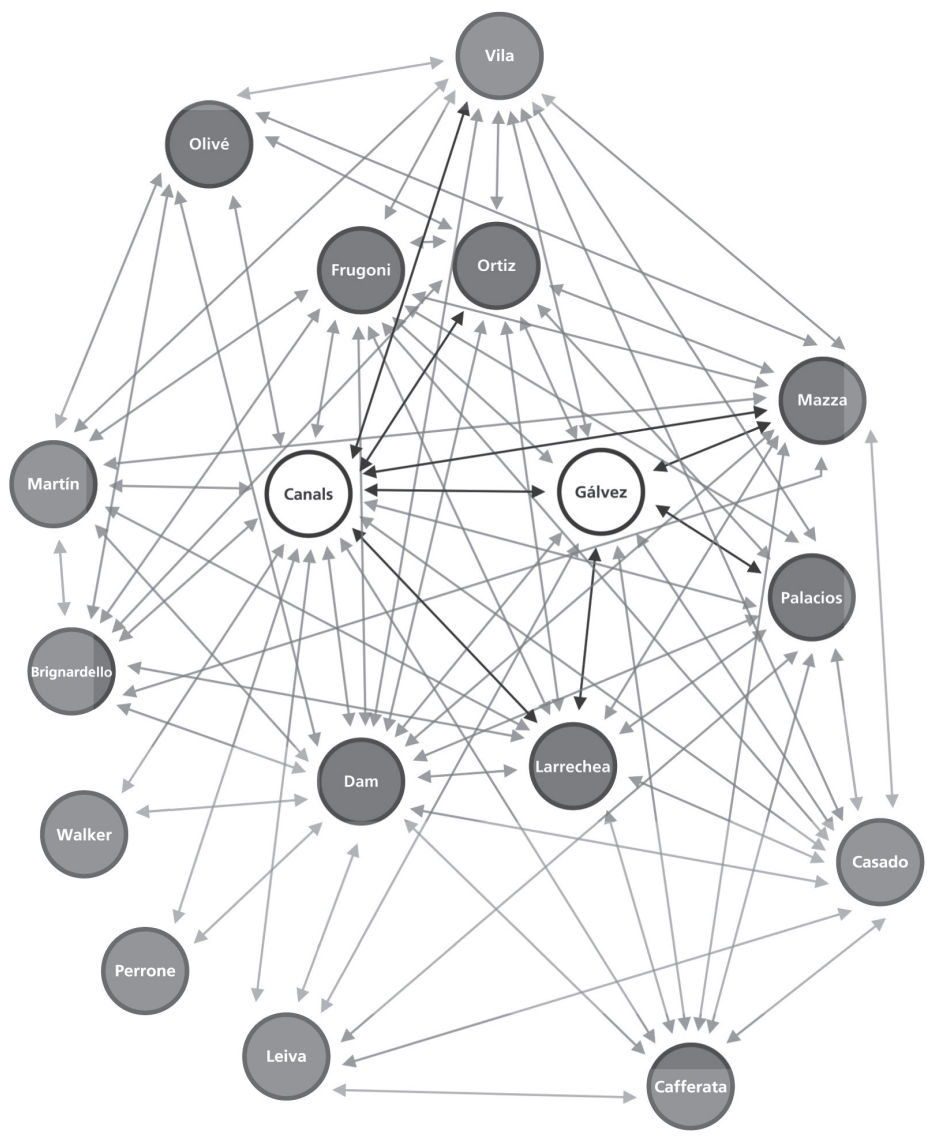

Nota: Los nexos graficados por flechas refieren a la existencia de, al menos, un tipo de vinculación entre los miembros referidos. El carácter de los vínculos corresponden a entramados políticos (pertenencia al Club del Pueblo), económicos (participación en sociedades anónimas o colectivas) o económicos-políticos (se registran los dos tipos de vínculos mencionados con anterioridad). Los fragmentos prioritarios de la red que explican el entramado político-económico que dio sentido a la obra pública, se encuentran destacados en color más oscuro.

La red fue elaborada con el programa Inkscape, versión 0.91, tomando en considereación las tramas vinculares en torno a las propuestas del empresario Canals referente a la obra pública, durante la gestión galvista.

Fuente: elaboración propia con base en la siguiente documentación: El Municipio, 6 de octubre de 1887, 14 de enero de 1890, 1 de septiembre de 1894 y 2 de septiembre de 1894; Caramelo, 9 de marzo de 1890; La Capital, 12 de octubre de 1890; Renovación, 17 de agosto de 1963; Convenio celebrado ad referéndum entre el señor intendente municipal y el contratista de adoquinado Juan Canals. Expedientes del Concejo Deliberante, 1888, vol. 2, f. 296, AHCMR; Estatutos de la Sociedad Anónima de Pavimentos y Afirmados de la Provincia de Santa Fe, 1889 y Estatutos de la Sociedad Anónima Construcciones Civiles de la Provincia de Santa Fe, 1889, vol. 4, fs. 533 y 541. Archivo del Registro Público de Comercio de Rosario, Rosario, Argentina (en adelante ARPCR); Carta de Juan Canals a Alfredo de Arteaga, 9 de febrero de 1890, 25 de febrero de 1890 y 21 de diciembre de 1890, Tribunales Comerciales, AGN; Venta de Juan Canals a José Gálvez. Venta de José Gálvez a Eloy Palacios. Protocolo del escribano Javier Munuce, 1890, fs. 17-18, 2325, ACESCSF; Concesión del Puerto a favor de Juan Canals, 1891, Archivo del Museo Histórico Provincial Julio Marc (en adelante AMHPJM). 
asimismo por empresarios que fueron sus socios en las propuestas relacionadas a este ámbito, como Palacios, accionista de las empresas vinculadas a la obra pública, Dam, socio principal de Canals en sus proyectos de construcción y Walker, proyectista del Palacio de Justicia, y por ediles que aprobaron sus proyectos y que estaban relacionados con él, ya sea por ser socios en algunas de sus empresas o por haber compartido, por el mismo espacio político, una banca en el Concejo Deliberante (Vila, Brignardello, Ortiz, entre otros). ${ }^{17}$

Asimismo, en el esquema puede verse, por un lado, la cohesión social de sus integrantes y, por el otro, la compleja trama relacional conformada por dos de los agentes a partir de los cuales se constituyó la red: Gálvez y Canals. La estructura presenta el carácter de una red egocéntrica, en tanto que se encuentra agrupada en torno a ese binomio (Rodríguez, 2013, p. 125). Paralelamente se evidencia que tanto Canals como Gálvez conformaron relaciones de primer orden, integradas por gente ligada a sus personalidades, y de segundo orden, es decir, las construidas por actores no vinculados directamente con ellos, sino unidos a otros miembros de la red. Este último elemento permite comprender los favores políticos recibidos por el empresario de parte de quienes integraban el círculo galvista -como Larrechea, Mazza y Cafferata- (El Municipio, 6 de octubre de 1887, 14 de enero de 1890).

Dos de los elementos que determinaron la trama vincular de la red fueron las intenciones que le dieron vida y el tipo de relación forjada entre sus miembros. ¿Por qué voluntariamente tanto empresarios como políticos "activaron" sus relaciones sociales en torno a la obra pública? El crecimiento económico del país y de la región pampeana reclamaba este tipo de inversiones. Paralelamente las administraciones provinciales y municipales se encontraban facultadas para vehiculizar este tipo de construcciones. Al calor de estos cambios esos vínculos latentes forjados entre empresariado y poder político, en los diferentes escenarios durante la etapa precedente, se activaron. El Estado delegó en el sector privado, mediante el mecanismo de la concesión, una parte de la responsabilidad que implicaba la prestación de servicios y obras públicas.

$\mathrm{Al}$ igual que el caso de otros empresarios de la obra pública, Canals recibió por parte de los hombres de poder ciertos favores (Pro-Ruiz, 2007, p. 30). A él se le adjudicó una diversidad de proyectos y, aunque sus concesiones siguieron las vías legales, existió un tráfico de influencias políticas

${ }^{17}$ Expedientes del Concejo Deliberante. Complementario de Archivo 1880 al 1899, 1899, libro C, f. 1483, AHCMR; Estatutos de la Sociedad Anónima de Pavimentos y Afirmados de la Provincia de Santa Fe, 1889. y Estatutos de la Sociedad Anónima Construcciones Civiles de la Provincia de Santa Fe, 1889, vol. 4, fs. 533 y 541. Archivo del Registro Público de Comercio de Rosario, Rosario, Argentina (en adelante ARPCR). 
para que sus proyectos se llevaran a cabo. Por poner un ejemplo, las presiones que el gobernador ejerció sobre el intendente Larrechea y algunos concejales como Mazza para la construcción de mataderos y mercados. Si bien las municipalidades eran autónomas en materia de obra pública, en la práctica el gobierno provincial ejercía cierta influencia (Adagio, 1993, p. 163). Sobre este tema, El Municipio aseveraba: "Esta vez [...] Gálvez [...] busca algo más [...] Lo traé [sic] el [...] propósito de darle los últimos toques a la propuesta de mataderos, mercados [...] Conferenciará con el intendente, Mazza y el presidente del Concejo Deliberante [...]" (El Municipio, 14 de enero de 1890). Si bien el periódico La Capital, con posterioridad, se refería a este proyecto aunque sin nombrar el entramado relacional que lo sustentaba -a diferencia de El Municipio- destacaba desde sus páginas los vínculos de amistad que ligaban a Canals con parte de la clase política (La Capital, 4 de abril de 1889).

En el ámbito municipal, la propuesta contó con el aval de algunos concejales como Mazza, quien expresó su aprobación a la propuesta en el diario La Nación. Sus declaraciones fueron objetadas por la prensa por considerar al concejal como un proponente oculto (El Municipio, 6 de abril de 1889). Pese a que las acusaciones sobre su posición no fueron enfatizadas por otros periódicos locales, La Capital, en una noticia referida al funcionamiento del Concejo Deliberante describía el papel central que él había adquirido en dicho asunto (La Capital, 9 de septiembre de 1889).

Respecto al intendente Larrechea se sabe que brindó al empresario una serie de favores en lo concerniente a sus proyectos de pavimentación. Por un lado, ese accionar debe explicarse por la ineficiencia de los controles que provenían de un Estado que se encontraba en construcción y, por el otro, debido a la penetración que ciertos empresarios experimentaron en el ámbito público. En más de una oportunidad se denunció a Larrechea por otorgarle a Canals, aun antes que los trabajos fueran terminados, los certificados correspondientes para que extrajera dinero de la cuenta municipal abierta a su nombre en el Banco Provincial. Por otra parte, el intendente y los concejales adherentes a las propuestas de Canals autorizaron algunas modificaciones contractuales que beneficiaban al empresario, como la utilización de materiales de menor costo. ${ }^{18}$ De igual forma la relación entre el empresario y el intendente fue de reciprocidad; las relaciones de reciprocidad se evidencian cuando "un individuo provee un servicio a otro o actúa para el beneficio de otros pero con la expectativa de que este 'servicio' le será devuelto" (Rodríguez, 2013, p. 106). Tiempo antes Canals, en su papel de urbanizador, había beneficiado a la intendencia con

\footnotetext{
${ }^{18}$ Convenio celebrado ad referéndum entre el señor intendente municipal y el contratista de adoquinado Juan Canals. Expedientes del Concejo Deliberante, 1888, vol. 2, f. 296, AHCMR.
} 
la donación de terrenos para la apertura de bulevares y el asesoramiento financiero para la ejecución de los trabajos. ${ }^{19}$

Otro segmento de la red estuvo integrada por algunos concejales de la ciudad como Ortiz, Vila y Olivé, quienes brindaron apoyo a los proyectos de Canals relacionados con la pavimentación de calles y la construcción del Palacio de Justicia. Los lazos construidos por Canals con algunos de ellos, tal era el caso de Ortiz, Vila y Olivé (figura clave en la vida del empresario, ya que su padre había sido quien le brindó ayuda para que Canals consiguiera su primer trabajo en Rosario) fueron lo suficientemente "fuertes" como para no necesitar la intervención del gobernador (Renovación, 17 de agosto de 1963).

Si colocamos nuestra atención en los primeros dos concejales mencionados podemos explicar la adhesión por ciertos beneficios económicos que podrían obtener de la concreción de tales proyectos. Tanto Ortiz y Vila, como otros miembros de la red (Palacios y Dam), formaron parte de dos sociedades anónimas denominadas Construcciones Civiles de la Provincia de Santa Fe y Pavimentos y Afirmados de la Provincia de Santa Fe, que tenían por objetivo absorber los contratos referidos al Palacio de Justicia, la cárcel provincial y el adoquinado de calles. ${ }^{20}$ Por otra parte, esos mismos actores fueron accionistas del Banco Sindical, dedicado a la compra y venta de inmuebles. Tal como consta en los documentos, el banco compraba y vendía terrenos valorizados por las construcciones de Canals. En la memoria municipal el intendente Carrasco describía esta situación: "se había llevado esa pavimentación a los suburbios". ${ }^{21}$

No obstante, fue la vinculación entre el gobernador y el empresario lo que imprimió la lógica de algunos tramos de la red. En palabras de uno de los protagonistas vislumbramos el reconocimiento del vínculo GálvezCanals a partir de la identificación que ellos hicieron del mismo. En una de sus cartas el empresario explicitaba: "Tuve a Gálvez [...] en casa cuando la inauguración de la exposición y arreglo de la política futura." ${ }^{22}$

El origen del vínculo entre el empresario y el gobernador se explica por la pertenencia de Canals al grupo de empresarios que, ligados al ex líder político del Club del Pueblo, Iriondo, dieron su apoyo a la figura

\footnotetext{
${ }^{19}$ Los datos se han extraído de un testimonio vertido por Canals en El Municipio del 6 de octubre de 1887 .

${ }^{20}$ Estatutos de la Sociedad Anónima de Pavimentos y Afirmados de la Provincia de Santa Fe, 1889, libro 5, f. 533; Estatuto de la Sociedad Anónima Construcciones Civiles de la Provincia de Santa Fe, 1890, libro 5, f. 541, ARPCR.

${ }^{21}$ Memoria que presenta el intendente municipal doctor Gabriel Carrasco correspondiente al año 1890, BA. Sobre una de las transacciones de dichos terrenos véase Copiador de Cartas, fs. 10-13. Archivo Torriglia, Rosario, Argentina.

${ }^{22}$ Carta de Juan Canals a Alfredo de Arteaga. Tribunales Comerciales, Buenos Aires, 1890, fs. 113-114, AGN.
} 
de Gálvez. Los lazos entre ambos se cristalizaron en algunos beneficios económicos, como las garantías estatales dadas a la empresa Ferrocarril Oeste Santafesino y la facilidad para la obtención de créditos en el Banco Provincial (Dalla-Corte, 2009, p. 48). ${ }^{23}$

Del tipo de favores que recibió el empresario por parte del gobernador ya hemos hecho mención, al describir el involucramiento que este manifestó en la aprobación de los proyectos. Pero ¿qué tipo de vínculo se forjó entre ambos?

Las vinculaciones entre Canals y Gálvez abarcaban operaciones en ámbitos como el inmobiliario y el financiero. Entre las propiedades que el empresario compró y vendió en Rosario existen transacciones que implicaban a ambos y a algunos miembros de la red, como Palacios. Un ejemplo de ello es la compra de un terreno transferido de Canals a Gálvez y de Gálvez a Palacios. ${ }^{24}$

Sin embargo, la documentación nos sugiere que ese entramado era más complejo. La denuncia efectuada contra Gálvez por el político Joaquín Lejarza pone en primer plano que Canals actuó como testaferro (es decir que realizó negocios a su nombre pero en realidad correspondían a otras personas) de algunos políticos entre los que se encontraba Gálvez. Asimismo, el testimonio revelaba que el empresario era la cara visible de una red que extraía del Banco Provincial fondos que no estaban destinados a sus propios fines, sino que cubrían las necesidades monetarias de sus "amigos" políticos, entre los que se encontraba Cafferata, futuro gobernador de la provincia (Caramelo, 9 de marzo de 1890). Luego que el banco fuera intervenido por una investigación, se reveló que los principales deudores de la entidad eran quienes integraban una parte de la red: Casado y la sociedad Canals, Dam y Cía. (La Capital, 12 de octubre de 1890).

Por otro lado, Lejarza afirmaba que Gálvez acudía a Canals no sólo para comprar bienes raíces, sino para beneficiarse de su crédito en el Banco Provincial y de sus capacidades de constructor. En esta oportunidad el político aseguraba:

¿Quiere decirme el señor Gálvez cómo ha pagado [...] una cuenta en el Banco Provincial [...]?- [...] -iHizo el pago en dinero, ó el banco descontó á [sic] terceros [...]? ¿Quiere decirme el nombre de esos terceros? [...]. Debe hablar de la otra gran manifestación: El [...] Banco Sindical, Canals [...] sobre las ruinas del Banco Sindical y del Banco de la Provincia aparece un sólo deudor que [...] se hace res-

${ }^{23}$ El Independiente, 10 y 11 de enero de 1882.

${ }^{24}$ Venta de Juan Canals a José Gálvez. Venta de José Gálvez a Eloy Palacios. Protocolo del escribano Javier Munuce, 1890, fs. 17-18, 23-25, ACESCSF. 
ponsable de la deuda de todos y carga [...] con los pecados de los autonomistas [...] (El Municipio, 1 de septiembre de 1894).

Los datos expuestos con anterioridad se corroboran con la información asentada en el expediente sucesorio de Canals. Allí se menciona el arreglo establecido entre Canals y la Asamblea de Accionistas del Banco Sindical, en el cual el empresario absorbía su activo y su pasivo. La deuda más abultada de dicha entidad la constituían las obligaciones impagas con el Banco Provincial. Por otra parte, en esa documentación constaba el acuerdo entre el empresario y esta última casa bancaria para la cancelación de sus deudas particulares. ${ }^{25}$

Lejarza aportaba más datos sobre la relación Canals-Gálvez:

[...] No sólo le compró el inmueble sino que, además el palacio fue construido por la empresa [...] de Canals ¿ De dónde salía el material? Del taller de Canals... ¿ ¿De dónde se llevaban los ladrillos? De los hornos de Canals [...] ¿Quién pagaba a los peones y constructores? Canals [...] ¿Quién dirigía la construcción?, el ingeniero Walker, empleado de Canals [...] Pero las cuentas no las pagaba usted, senador Gálvez, sino el gran empresario Canals [...] ¿Quiere el ex gobernador Gálvez una prueba más aplastadora de su "conjunción ilícita" con el [...] empresario [...] y deudor [...] del banco de la provincia...? (El Municipio, 2 de septiembre de 1894). ${ }^{26}$

Tal como puede observarse en esta trama de vínculos, hay un elemento central a partir del cual giran algunas de estas relaciones, nos referimos al mencionado Banco Provincial. El mismo había sido creado con el objetivo de centralizar el crédito local y la emisión de dinero que se encontraba monopolizado por el Banco de Londres y Río de la Plata (Gallo, 1971, pp. 164, 166). El Banco era una sociedad anónima de capitales mixtos cuyo principal accionista era el Estado y, en menor medida, los miembros de la burguesía local, entre los que se encontraban Canals y Palacios. Para el caso del proyecto de adoquinado esta entidad era central, ya que allí se encontraba depositada la totalidad del empréstito que la municipalidad había adquirido para la ejecución de los trabajos. Según la documentación, Palacios, como director, extrajo de esa cuenta fondos de manera clandestina para satisfacer exigencias que el banco, ya en bancarrota por los efectos de la crisis y sus malos manejos internos, no podía solventar (El Municipio, 5 de diciembre de 1899). ${ }^{27}$ Sin embargo, tal como se ha demostrado en el

\footnotetext{
${ }^{25}$ Juan Canals su sucesión hoy su concurso, 1901, leg. 9010, f. 76, APJN.

${ }^{26}$ El testimonio de Lejarza está haciendo referencia a la casa de Gálvez en Rosario, a Walker y a la empresa de hornos de ladrillo de Canals.

${ }^{27}$ Carta de Juan Canals a Alfredo de Arteaga. Tribunales Comerciales, 1890, fs. 37-43, AGN.
} 
testimonio de Lejarza y en la memoria municipal de 1890, donde se describe el manejo de la cuenta de Canals en el Banco Provincial, ese dinero sirvió para cubrir las necesidades de otros miembros de la red como Gálvez (El Municipio, 2 de septiembre de 1894). ${ }^{28}$

Por otra parte, el vínculo entre Palacios y Canals no sólo se explica por el funcionamiento que revistió el Banco Provincial, sino también por los intereses de Palacios en el negocio de la obra pública. Al igual que Vila y Ortiz, Palacios fue uno de los principales accionistas de las sociedades que se constituyeron con el fin de absorber las construcciones de Canals. ${ }^{29}$

Finalmente, y como corolario de la crisis de 1890, las tramas vinculares descritas se tensionaron y rompieron, una de ellas fue la relación entre Canals y Palacios. En su correspondencia, el empresario destacaba la falta de reciprocidad de algunos favores de Palacios ante sus pedidos de asistencia financiera. Por otra parte, otros miembros de la red como Vila y Dam se vieron arrastrados por la quiebra de Canals, el primero por ser acreedor y el segundo por ser el principal socio. ${ }^{30}$ Esto demuestra que los actores ensayaron ciertas estrategias, es decir que sus acciones fueron el resultado de determinadas decisiones cuyo objetivo fue aprovechar las oportunidades que les ofrecía el medio, pero estas se ejercieron con racionalidad limitada (Pro-Ruiz, 1995, p. 68). Es decir que la orientación de las mismas no aseguró el éxito de sus trayectorias. Ellas estuvieron determinadas por las circunstancias económicas no previstas -como la crisis económica de 1890- y las lógicas de las tramas vinculares, donde no siempre operó una relación de reciprocidad mutua entre sus miembros.

\section{CONSIDERACIONES FINALES}

La obra pública durante la etapa galvista ha sido el escenario para analizar la vinculación entre empresariado y poder político en Santa Fe. Tal como hemos dicho, el caso analizado es representativo de la burguesía rosarina en tanto que estos sectores, si bien no detentaron lugares significativos en los cargos gubernamentales a nivel provincial, ejercieron su influencia en la escena política a través de la configuración de una trama vincular que involucraba tanto a políticos como a empresarios. En esa trama la

${ }^{28}$ Memoria que presenta el intendente municipal doctor Gabriel Carrasco correspondiente al año 1890,1891 , BA.

${ }^{29}$ Estatutos de la Sociedad Anónima de Pavimentos y Afirmados de la Provincia de Santa Fe, 1889, libro 5, f. 533; Estatuto de la Sociedad Anónima Construcciones Civiles de la Provincia de Santa Fe, 1890, libro 5, f. 541, ARPCR.

${ }^{30}$ Carta de Juan Canals a Alfredo de Arteaga. Tribunales Comerciales, 1890, f. 37, AGN; Juan Canals su sucesión hoy su concurso, 1901, leg. 9010, APJN. 
obra pública cumplió una función directriz, en tanto que a partir de ella se combinaron otros negocios relacionados con los ámbitos inmobiliario, comercial, bancario y de la construcción.

En ese escenario la burguesía local se acercó, a través de esas redes, al Estado en búsqueda de beneficios económicos. Al igual que otros grupos burgueses, ellos compartieron una concepción patrimonial del Estado que respondía a las pautas culturales del liberalismo decimonónico donde existía una frontera lábil entre intereses públicos y privados.

Esa imbricación de intereses se fusionó en un momento donde las burguesías dejaban su impronta material en las ciudades y donde los Estados, por medio del sistema de concesiones, delegaban en ellos algunos servicios, entre los que se destacaban las obras y servicios públicos.

De este modo la trama vincular entre empresariado y poder político, contrariamente a lo acaecido en el escenario valenciano del siglo XIX donde los empresarios combinaban su función pública con los negocios privados- se estructuró con base en lo que podríamos llamar una división de tareas entre quienes se dedicaban a la vida política y quienes se orientaban a los emprendimientos económicos (Pro-Ruiz, 2007, p. 52). Si bien esos grupos operaron en el espacio político municipal, estos eran entes administrativos, donde la penetración de las decisiones gubernamentales esgrimidas desde el espacio provincial los convertía en escenarios dependientes.

Los vínculos de reciprocidad construidos entre empresariado y poder político fueron utilizados estratégicamente por los actores para operar al mismo tiempo en uno y otro ámbitos. Esas relaciones en algunos momentos se circunscribieron a las vías legales -respetabilidad en el proceso licitatorio- y en otros funcionaron mediante la lógica patrimonial con la que operaban los grupos burgueses, es decir que usufructuaron ciertos beneficios económicos ante la incapacidad de los controles estatales en relación con la utilización de los dineros públicos y la ejecución de las obras. Sin embargo, esa manera de funcionar no estuvo exenta de riesgos y dificultades, como lo demuestra el caso analizado, la misma no aseguró ni la efectivización de las obras, ni el éxito de las trayectorias empresariales debido a los riesgos que implicaba el ámbito de la obra pública, a las condiciones económicas adversas, pero también, a la ruptura de las relaciones de reciprocidad que, en algunos momentos, operó al interior de ese entramado social. 


\section{LISTA DE REFERENCIAS}

Adagio, N. (1993). Rosario urbana: la gestión municipal desde 1886-1890. Estudios Sociales, 4, 161-173.

Alonso, P. (2004). Introducción. En P. Alonso (comp.), Construcciones impresas. Panfletos, diarios y revistas en la formación de los Estados nacionales en América Latina, 18201920 (pp. 7-12). Buenos Aires: Fondo de Cultura Económica.

BANDIERI, S. (2000). Neuquén, grupos de poder, estrategias de acumulación y prácticas políticas. Anuario del IEHS, 15, 179-208.

BANDieri, S. (2005). Asuntos de familia... la construcción del poder en la Patagonia: el caso de Neuquén. Boletín del Instituto de Historia Argentina y Americana Dr. Emilio Ravignani, 28, 65-94.

Bertrand, M. (2012). De la familia a la red de sociabilidad. Revista Páginas, 4(6), 47-80.

BoIXAidós, M. C. (2000). Tramas de una ciudad, 1870-1895. Elite urbanizadora, infraestructura, poblamiento. Córdoba: Ferreyra Editor.

Boixaidós, M. C. (2010). La ciudad en disputa. Prácticas de enriquecimiento de la elite dirigente a fines del siglo XIX. En C. TCACH (coord.), Córdoba bicentenaria. Claves de su historia contemporánea (pp. 37-70). Córdoba: Universidad Nacional de Córdoba.

Bolsi, F. (2013). Familia, estrategia de reproducción social y comercio de exportación en Tucumán, Argentina, 1780-1820. Una aproximación a partir de la familia Posse. Anuario de Estudios Americanos, 70(1), 129-156. DOI: 10.3989/aeamer.2013.1.05

Bonaudo, M. (1999). De representantes y representados: Santa Fe finisecular (18831893). En H. SÁbato (coord.), Ciudadanía política y formación de las naciones. Perspectivas Históricas de América Latina (pp. 270-294). México: Fondo de Cultura Económica.

Bonaudo, M. (2015). Repensando el partido/facción en la experiencia latinoamericana. Illes I Imperis, 17, 15-42. Recuperado de http://www.raco.cat/index.php/ IllesImperis/article/view/299478

Bonaudo, M. y Sonzogni, E. (1998). Empresarios y poder político en el espacio santafesino (1860-1890). Carlos Casado y su estrategia de acumulación. Historia y Grafía, 11, 39-64.

Bonaudo, M. y Sonzogni, E. (1999). Los grupos dominantes entre la legitimación y el control. En M. Bonaudo (dir.), Historia Argentina. Liberalismo, Estado y orden burgués (1852-1880) (pp. 27-96). Barcelona: Sudamericana.

Bonaudo, M. y Sonzogni, E. (2000 y 2001). Conflictos y armonías. Estados y facciones burguesas en la realidad santafesina. Travesía, 5-6, 7-28.

BRAGONI, B. (1993). Redes, inmigración y movilidad social en Mendoza: racionalidad empresaria y modos de relación política en una parentela finisecular 1880-1930. Estudios Migratorios Latinoamericanos, 8(24), 171-204.

Bragoni, B. (1999). Los hijos de la revolución. Familia, negocios y poder en Mendoza en el siglo XIX. Buenos Aires: Taurus. 
Bravo, M. C. y CAmpi, D. (2000). Elite y poder en Tucumán, Argentina, segunda mitad del siglo XIX: problemas y propuestas. Secuencia, 47, 75-104. DOI: 10.18234/ secuencia.v0i47.690

Connolly, P. (1993). Lo público y lo privado de las obras públicas en México: los primeros cien años. Sociológica, 8(22), 103-124.

Connolly, P. (1999). El desagüe del Valle de México. Política infraestructural, contratismo y deuda pública, 1890-1900. En S. Kuntz, y P. Connolly, Ferrocarriles y obras públicas (pp. 191-219). México: Instituto de Investigaciones Dr. José María Luis Mora/Colegio de Michoacán/El Colegio de México/Instituto de Investigaciones Históricas.

Cragnolino, S. (1986-1987). Políticas, facciones y participación política en Santa Fe (1868-1884). Anuario de la Escuela de Historia, 12, 423-446.

Dalla-Corte, G. (2009). La consistencia de la red social: El Ferrocarril Oeste Santafesino entre la Argentina pampeana y el Chaco Paraguayo (1880-1900). En P. García (ed.), Dinámicas del poder local en América Latina. Siglos XIX y XXI. Barcelona: Taller de Investigaciones Andino-Amazónicos/Universidad de Barcelona.

Eujanian, A. y SÁnchez-Román, S. (1993). El papel de la prensa en la constitución de un orden urbano en Rosario hacia fines del siglo XIX. La Capital de Rosario 18901893. Anuario de la Escuela de Historia, 15, 117-126.

Fernández, S., Videla, O. y Pons, A. (1999 y 2000). Una burguesía local dentro de un espacio regional, Rosario 1880-1912. Un intento de caracterización. Travesía, 3-4, 233-245.

Fortuny, D. y Rodes, M. (2005). La lucha en su tinta. El caso de un diario rosarino en el periodo de las revoluciones radicales: El Municipio, 1890-1905 (Seminario de grado inédito). Universidad Nacional de Rosario, Argentina.

Gallo, E. (1971). El gobierno de Santa Fe y el Banco de Londres y Río de la Plata (1876). Revista Latinoamericana de Sociología, 7(2-3), 147-174.

GALlo, E. (2000). La consolidación del Estado y la reforma política (1880-1914). En Academia Nacional de la Historia, Nueva historia de la Nación Argentina. Tomo 4: La Configuración de la República Independiente (1880-1914) (pp. 511-541). Buenos Aires: Planeta.

Garcilazo, R. (2013). Un tema conflictivo: la propuesta de Juan Canals para la construcción de tabladas, mataderos y mercados de abasto, Rosario, 1889. Secuencia, 86, 113-135. DOI: 10.18234/secuencia.v0i86.1195

GARCILAzO, R. (2015). Empresarios pampeanos, entre la fortuna, el poder y la pervivencia. El caso de Juan Canals, Rosario 1870-1901 (Tesis de doctorado). Universidad Nacional de Rosario, Argentina.

HALPERIn, T. (1992). Clase terrateniente y poder político en Buenos Aires (1820-1930), Cuadernos de Historia Regional, 15, 11-46.

Herrera, C. (2004). Élites y poder en Argentina y España en la segunda mitad del siglo XIX (Tesis de doctorado). Universidad Complutense Madrid, España. 
Herrera, C. (2011). Estrategias de inversión y prácticas de transmisión patrimonial en el siglo XIX. Los Frías una familia de la elite tucumana (Argentina). América Latina en la Historia Económica, 18(2), 94-122. DOI: 10.18232/alhe.v18i2.480

Hora, R. (2005). Los terratenientes de la pampa Argentina. Una historia social y política 1860-1945. Buenos Aires: Siglo Veintiuno Editora Iberoamericana.

Hora, R. (2009). La Liga Agraria y la formación del ruralismo político en la Argentina. Buenos Aires: Siglo Veintiuno.

JÁuregui, A. (1993). El despegue de los industriales argentinos. En W. Ansaldi, A. Pucciarelli y J. Villarreal (eds.), La Argentina en la paz de dos guerras 1914-1945 (pp. 161-192). Buenos Aires: Biblos.

LANCIOTTI, N. (2009). De rentistas a empresarios. Inversión inmobiliaria y urbanización en la pampa argentina. Rosario 1880-1914. Santa Fe: Universidad Nacional del Litoral.

Lanciotti, N. y Lluch, A. (2010). Presentación. Fracasos empresariales. América Latina, siglos XIX y XX. Anuario del IEHS, 25, 353-358.

Ley Nacional de 1876. Congreso Nacional. Cámara de Senadores 1876 (1876). Buenos Aires: s. d.

LOTERSZTAin, I. (2010). Los bancos se roban con firmas. Corrupción y crisis en 1890. Buenos Aires: Turmalina.

MARChESE, S. (1993). Empresarios en búsqueda de un espacio político. La CACIP: realidad interna y rumbos externos. En W. Ansaldi, A. PuCciarelli y J.Villarreal (eds.), La Argentina en la paz de dos guerras 1914-1945 (pp. 107-133). Buenos Aires: Biblos.

Marco, M. A. DE (2002). El contralor del estado en la transformación argentina. Tierras, ferrocarriles y obras públicas en Santa Fe. Rosario: Universidad Católica Argentina.

Marquiegui, N. y Tartaglia, M. T. (2003). De la sociedad anónima por acciones al cooperativismo: el caso de la Cooperativa Eléctrica y de Servicios Públicos Lujanense Ltda., 1911-2000. Capaya, 5, 84-104.

Megías, A. (2010). Movilización y turbulencias políticas. Rosario en la segunda mitad del siglo XIX. En AA.VV., Los desafíos de la modernización. Rosario 1890-1930. Rosario: Universidad Nacional de Rosario Editora.

Moutoukias, Z. (1995). Narración y análisis en la observación de vínculos y dinámicas sociales: el concepto de red personal en la historia social y económica. En M. BJerg y H. Otero (comps.), Inmigración y redes sociales en la Argentina Moderna (pp. 221-241). Buenos Aires: Centro de Estudios Monetarios Latinoamericanos/ Instituto de Estudios Históricos y Sociales.

PAZ, G. (2003). El gobierno de los “Conspicuos” familia y poder en Jujuy 1853-1875. En H. Sábato y A. LetTieri (comps.), La vida política en la Argentina del siglo XIX. Armas, votos y voces (pp. 223-241). Buenos Aires: Fondo de Cultura Económica.

Ponce-Leiva, P. y Amadori, A. (2008). Redes sociales y ejercicio del poder en América Hispana: consideraciones teóricas y propuestas de análisis. Revista Complutense de Historia de América, 34, 15-42. 
Pro-Ruiz, J. (1995). Las elites de la España Liberal: clase y redes en la definición del espacio social (1880-1931). Revista de Historia Social, 21, 47-69.

Pro-Ruiz, J. (2007). Poder político y poder económico en el Madrid de los Moderados (1844-1854). Ayer, 66, 27-55.

Ramos, J. (1916). El derecho público de las provincias argentinas. Buenos Aires: Facultad de Derecho y Ciencias Sociales.

Rapalo, M. E. (2012). Patrones y obreros. La ofensiva de la clase propietaria 1918-1930. Buenos Aires: Siglo Veintiuno.

Regalsky, A. y Salerno H. (2008). Financiamiento e inversión pública en la Argentina en un periodo en transición, 1900-1935. Un enfoque general y dos estudios de caso. Revista de Historia Económica, 27, 205-246. DOI: 10.1017/S0212610900000756

Richard-Jorba, R. y Bragoni, B. (1998). Empresarios-políticos y el control del estado. Renovación de la elite y construcción de una economía regional en el marco nacional. Mendoza, Argentina. 1850-1890. Historia y Grafía, 11, 13-38.

RocCHI, F. (2000). Un largo camino a casa: empresarios, trabajadores e identidad industrial en la Argentina 1880-1930. En J. SuRIANO (comp.), La cuestión social en la Argentina 1870-1943 (pp. 159-190). Buenos Aires: La Colmena.

Rodríguez, J. (2013). Cómo utilizar el análisis de Redes Sociales para temas de Historia. Signos Históricos, 29, 102-141.

SolveirA, B. (2009). El servicio de agua corriente en la ciudad de Córdoba (Argentina), 1880-1935. Agricultura, Sociedad y Desarrollo, 6(3), 253-276.

VAlencia, M. (1993). La vanguardia de la Sociedad Rural y su actuación parlamentaria. En M. Bonaudo y A. Puciarelli (comps.), La problemática agraria. Nuevas aproximaciones (pp. 121-139). Buenos Aires: Centro Editor de América Latina.

Ventura, S. (2003). El diario El Municipio de Deolindo Muñoz y la redefinición "política" del régimen municipal. Prohistoria, 7, 233-249.

Videla, O. y FERnÁNDEZ, S. (2001). La evolución económica rosarina durante el desarrollo agroexportador. En R. FALCón y M. STANLEy (dirs.), La historia de Rosario (pp. 33- 110). Buenos Aires: Homo Sapiens.

\section{Otras Fuentes}

\section{Archivos}

ACESCSF Archivo del Colegio Público de Escribanos Segunda Circunscripción Santa Fe, Rosario, Argentina.

AGN Archivo General de la Nación, Buenos Aires, Argentina.

AHCMr Archivo Histórico del Concejo Municipal de Rosario, Rosario, Argentina.

AmHrjm Archivo Museo Histórico Provincial Julio Marc, Rosario, Argentina.

APJN Archivo del Poder Judicial de la Nación, Buenos Aires, Argentina.

ARPCR Archivo del Registro Público de Comercio de Rosario, Rosario, Argentina. 
AT

Archivo Torriglia, Rosario, Argentina.

BA

Biblioteca Argentina Dr. Juan Álvarez. Municipalidad de Rosario, Rosario, Argentina.

\section{Hemerografía}

Caramelo, Rosario, 1890.

El Independiente, Rosario, 1882.

El Municipio, Rosario, 1887,1889, 1890, 1894, 1899.

La Capital, Rosario, 1889, 1890.

Renovación, Córdoba, 1963. 